\title{
Rapamycin enhanced the antitumor effects of doxorubicin in myelogenous leukemia K562 cells by downregulating the mTOR/p70S6K pathway
}

\author{
JIE LI ${ }^{1}$, WENJING LIU ${ }^{2}$, HONGLING HAO ${ }^{1}$, QIUYI WANG ${ }^{2}$ and LIYING XUE ${ }^{2}$ \\ ${ }^{1}$ Department of Hematology, Hebei General Hospital; ${ }^{2}$ Department of Pathology, \\ Hebei Medical University, Shijiazhuang, Hebei 050000, P.R. China
}

Received October 15, 2018; Accepted June 11, 2019

DOI: $10.3892 / 01.2019 .10589$

\begin{abstract}
Chronic myelogenous leukemia (CML) is a common hematological malignancy. Some patients progressing to the blast phase develop chemotherapeutic drug resistance. In the authors' previous study, it was found that the mammalian target of rapamycin (mTOR) pathway was activated in CML and that rapamycin inhibited the proliferation of K562 cells. Targeting the mTOR pathway may be used in combination with chemotherapeutic drugs to enhance their efficacy and overcome multidrug resistance. The aim of the present study was to investigate the effects of rapamycin and doxorubicin on K562 cell proliferation following the combination treatment, and further focus on confirming whether rapamycin enhanced the antitumor effects of doxorubicin by downregulating the mTOR/ribosomal protein S6 kinase (p70S6K) pathway. It was found that rapamycin and doxorubicin significantly decreased the viability of K562 cells. The apoptotic cells were more frequently detected in rapamycin and doxorubicin treatment groups $(25.50 \pm 1.25 \%)$. Both drugs decreased Bcl-2 and increased Bax expression in K562 cells. Rapamycin and doxorubicin also reduced the phosphorylation levels of mTOR and p70S6K. Meanwhile, p70S6K-targeting small interfering (si)RNA and doxorubicin inhibited cell proliferation and regulated key factors of the cell cycle. In addition, the exposure of cells to p70S6K siRNA and doxorubicin significantly increased cell apoptosis, as compared with single treatment.
\end{abstract}

Correspondence to: Dr Jie Li, Department of Hematology, Hebei General Hospital, 348 West Heping Road, Shijiazhuang, Hebei 050000, P.R. China

E-mail: doclijie@163.com

Professor Liying Xue, Department of Pathology, Hebei Medical University, 361 East Zhongshan Road, Shijiazhuang, Hebei 050000, P.R. China

E-mail: xueliying123@163.com

Key words: chronic myelogenous leukemia, rapamycin, doxorubicin, mammalian target of rapamicin, ribosomal protein S6 kinase
These results suggested that rapamycin could enhance the antitumor effects of doxorubicin on K562 cells by downregulating mTOR/p70S6K signaling. Targeting the mTOR/p70S6K pathway may be a new therapeutic approach for leukemia.

\section{Introduction}

Myeloid leukemia is a common hematological malignancy that is subdivided into acute myelogenous leukemia (AML) and chronic myelogenous leukemia (CML). CML is a myeloproliferative disorder characterized by the Philadelphia chromosome, a fusion of chromosomes 9 and 22, that gives rise to the $\mathrm{Bcr} / \mathrm{Abl}$ oncogene $(1,2)$. Bcr/Abl kinase inhibitors, such as imatinib, yield an outstanding clinical response in the chronic phase of CML. However, certain patients that progress to the blast phase with a decreased responsiveness develop resistance to Bcr/Abl kinase inhibitors (3). Doxorubicin, one of the most widely used antitumor drugs inleukemia treatment, exerts its proapoptotic effects through disturbing DNA function and inducing DNA damage. To date, the DA regimen (mainly containing doxorubicin and cytatabine) has been the standard treatment for AML, but is not effective for patients in the blast phase. New effective approaches must be explored to enhance the therapeutic efficacy against leukemia.

It has been established that the activation of the mammalian target of rapamycin (mTOR) pathway is closely associated with cell proliferation and differentiation in several types of human cancer, such as breast, lung, and pancreatic cancer (4-7). In addition, the mTOR pathway has been found to be activated in leukemia cells, especially in cell lines expressing Bcr/Abl (8-11). Previous studies demonstrated that the mTOR pathway was activated in myeloid leukemia, including CML, and mTOR inhibitor (rapamycin, sapanisertib) could arrest cells at the $G_{0} / G_{1}$ phase and increase apoptosis in leukemia cells (12-14). mTOR is a serine/threonine kinase which plays important roles in the phosphatidylinositol-4,5-bisphosphate 3-kinase (PI3K)/Protein Kinase B (AKT)/mTOR pathway. It was reported that $\mathrm{PI} 3 \mathrm{~K}$, induced by $\mathrm{Bcr}-\mathrm{Abl}$ through a direct association with its regulatory subunit, could activate mTOR upon phosphorylation of AKT (15). A recent study showed that a dualPI3K/mTOR inhibitor effectively inhibited cell proliferation and induced apoptosis by downregulating the 
PI3K/mTOR pathway (16). Further evidence that rapamycin combined with celecoxib could enhance the antitumor effects of single treatment on CML cellswas provided (17). Therefore, targeting the mTOR pathway may increase cell sensitivity to chemotherapeutic drugs and serve as a new therapeutic approach for leukemia. However, the precise mechanisms through which rapamycin may have synergistic effects with chemotherapeutic drugs in leukemia remained unclear.

The activation of mTOR (phosphorylated-mTOR) could phosphorylatetwo major downstream targets, ribosomal protein S6 kinase (p70S6K) and eukaryotic initiation factor 4E-binding protein 1 (4E-BP1). Upon its phosphorylation, p70S6K induces protein synthesis and cell survival, and increases the translation of 5'-terminal oligopyrimidine tract mRNAs (18-20). This is important for mitogen-induced cell proliferation and chemotherapeutic drug resistance in cancer cells $(21,22)$. The authors' previous study showed that p70S6K and 4E-BP1 were overexpressed and phosphorylated in CML bone marrow and K562 cells (12). It was therefore speculated that rapamycin could enhance the antitumor effects of chemotherapy on leukemia cells through downregulating mTOR signaling.

In the present study, cell growth and apoptosis in K562 cells was investigated following rapamycin and doxorubicin treatment. In addition, the effects of p70S6K-targeting siRNA and doxorubicin on K562 cells were closely investigated. The present study tried to confirm whether rapamycin enhanced the antitumor effects of doxorubicin by downregulating the mTOR/p70S6K pathway in this preliminary study. Determining the underlying mechanism may help define this new therapeutic target for clinical application in hematologic malignancies.

\section{Materials and methods}

Chemicals and reagents. The K562 cell line was purchased from the Beijing Institute for Cancer Research. The primary antibodies used in this study include: Rabbit anti-human mTOR (1:1,000; cat. no. 2983), phosphorylated (phospho/p)-mTOR (1:1,000; cat. no. 5536), p70S6K (1:800, cat. no. 2708) and phospho-p70S6K (1:500; cat. no. 9234) were purchased from Cell Signaling Technology, Inc.; Rabbit anti-human $\beta$-actin (1:10,000; cat. no. AC026) monoclonal antibody was bought from ABclonalBiotech Co., Ltd.; rabbit anti-human Bax (1:500; cat. no. sc-23959) and Bcl-xL (1:500; cat. no. sc-8392), and mouse anti-human Bcl-2 (1:500; cat. no. sc-509) antibodies were bought from Santa Cruz Biotechnology, Inc.; and rabbit anti-human cyclin dependent kinase (CDK)4 (1:5,000; cat. no. ab108357), CDK6 (1:20,000; cat. no. ab124821), cyclin B1 (1:10,000; cat. no. ab32053) and cyclin D1 (1:200; cat. no. ab16663) were purchased from Abcam. Goat anti-Mouse IgG (H\&L), horseradish peroxidase (HRP) conjugated secondary antibody (1:10,000; cat. no: 074-1806; S0002) and Goat anti-Rabbit IgG (H\&L), HRP conjugated secondary antibody (1:5,000; cat. no: 074-1506; S0001) were purchased from Affinity Biosciences.

Cell culture and treatment. K562 cells were cultured in RPMI1640 (Gibco; Thermo Fisher Scientific, Inc.) supplemented with penicillin $(100 \mathrm{U} / \mathrm{ml})$, streptomycin $(100 \mathrm{U} / \mathrm{ml})$ and $10 \%$ fetal bovine serum (Gibco; Thermo Fisher Scientific, Inc.). Doxorubicin and rapamycin were diluted in solvent dimethyl sulfoxide (DMSO; Merck KGaA). K562 cells were treated with various concentrations of rapamycin and/or doxorubicin.

Cell counting kit-8 (CCK-8) assay. Doxorubicin was dissolved in DMSO at a concentration of $1 \mathrm{mM}$ as the primary stock solution and stored at $4^{\circ} \mathrm{C}$. It was reported that the distribution volume of doxorubicin varies markedly in different patients or for different cell lines (23-26). Therefore, to investigate its effects on cell proliferation, K562 cells were cultured with various concentrations of doxorubicin $(0.03125,0.0625$, $0.125,0.25,0.5,1,2$ and $4 \mu \mathrm{M}$ ) for $24 \mathrm{~h}$ at $37^{\circ} \mathrm{C}$. After cells were incubated with the CCK- 8 reagent (DojindoMolecular Technologies, Inc.) for $4 \mathrm{~h}$, the cytotoxic effect of doxorubicinon K562 cells was measured on a spectrophotometer microplate reader (BioTek Instruments, Inc.) at a wavelength of $450 \mathrm{~nm}$. Cell viability was assayed and compared to the control group. The sensitivity of cells to doxorubicin was measured by $\mathrm{IC}_{50}$. The concentration of rapamycin $(10,20$ and $40 \mathrm{nM}$ ) was added to K562 cells according to the authors' previous studies $(12,14)$. The interaction between rapamycin and doxorubicin was assessed using the combination index (CI) $(27,28)$. The CI was used to identify antagonistic (CI>1), additive $(\mathrm{CI}=1)$ or synergistic $(\mathrm{CI}<1)$ interactions.

Flow cytometry (FCM). K562 cells from different groups treated with rapamycin $(20 \mathrm{nM})$, doxorubicin $(0.5 \mu \mathrm{M})$ and a combination of both, were collected and washed twice with phosphate-buffered saline (PBS) and harvested in the buffer (PBS-0.05\% trypsin). K562 cells were incubated with $5 \mu 1$ Annexin $\mathrm{V}$ and $10 \mu \mathrm{l}$ propidium iodide (PI) in the dark for $5 \mathrm{~min}$, and then resuspended in $1 \mathrm{X}$ binding buffer. Briefly, cell apoptosis was analyzed using an Annexin V/PI apoptosis detection kit [Hangzhou Multi Sciences (Lianke) Biotech Co., Ltd.] according to the manufacturer's protocol.

siRNA transfection. $\mathrm{K} 562$ cells $\left(1.0 \times 10^{5} / \mathrm{ml}\right)$ were seeded in 6 -well plates and transfected with $50 \mathrm{nM}$ siRNA duplexes using Lipofectamine ${ }^{\mathrm{TM}} 2000$ reagent according to the manufacturer's protocol (Thermo Fisher Scientific, Inc.). A total of $48 \mathrm{~h}$ following transfection of p70S6K siRNA (5'-GACAAAAUC CUCAAAUGUA-3') and negative control siRNA (5'-GGC TACGTCCAGGAGCGCA-3'; GE Healthcare Dharmacon, Inc.), the inhibition efficiency at mRNA and protein levels was estimated using reverse transcription-quantitative polymerase chain reaction (RT-qPCR) and western blot analysis.

Western blot analysis. Total cell proteins were extracted from K562 cells treated with rapamycin and/or doxorubicin using lysis buffer (1\% Triton X-100, $150 \mathrm{mM} \mathrm{NaCl}, 2$ mM EDTA, $50 \mathrm{mM}$ Tris- $\mathrm{HCl}$ ) supplemented with phosphatase inhibitor cocktail. After protein concentration was measured by Gen5 1.0 software (BioTek Instruments, Inc.) on a spectrophotometer microplate reader (BioTek Instruments, Inc.), 20-40 $\mu$ g protein was run on a $10-15 \%$ sodium dodecyl sulfate polyacrylamide gel electrophoresis gel and transferred to a polyvinylidinedifluoride membrane. Following blocking non-specific binding sites with $5 \%$ nonfat dry milk in tris-buffered saline with $0.05 \%$ Tween at $37^{\circ} \mathrm{C}$ for $60 \mathrm{~min}$, the membranes were incubated 
Table I. Primers for reverse transcription-quantitative PCR amplification.

\begin{tabular}{ll} 
Primers & \multicolumn{1}{c}{ Sequence } \\
\hline CDK4-sense & 5'-AGTTCGTGAGGTGGCTTTAC-3' \\
CDK4-antisense & 5'-GCCTTGTCCAGATATGTCCTTAG-3' \\
CDK6-sense & 5'-CTGCCTTGTTGGCAAAGTATC-3' \\
CDK6-antisense & 5'-CCAGGTAGAAGGACTGCATTAG-3' \\
Cyclin D1-sense & 5'-CCACTCCTACGATACGCTACTA-3' \\
Cyclin D1-antisense & 5'-GGACTGAAAGTGCTTGGAAATG-3' \\
Cyclin B-sense & 5'-GGTGTCACTGCCATGTTTATTG-3' \\
Cyclin B-antisense & 5'-CGAAGGAAGTGCAAAGGTAGA-3' \\
p70S6K-sense & 5'-CAAGGTGAGGGAGATAGGGATA-3' \\
p70S6K-antisense & 5'-AAGGAAGGTAGACAGCAGAAAC-3'
\end{tabular}

$\mathrm{CDK}$, cyclin dependent kinase; p70S6K, ribosomal protein S6 kinase.

with primary antibodies against mTOR, p-mTOR, p70S6K, p-p70S6K, Bcl-2, Bax, Bcl-xL, CDK4, CDK6, Cyclin B1 and CyclinD1at $4^{\circ} \mathrm{C}$ overnight. Next, the membranes were probed with horseradish peroxidase-conjugated secondary antibody $(1: 5,000)$ for $60 \mathrm{~min}$ at $37^{\circ} \mathrm{C}$. Subsequently, the immunoreactive membranes were developed using Pierce ${ }^{\mathrm{TM}}$ ECL Western Blotting Substrate (cat. no. 32109; Thermo Fisher Scientific, Inc. cat. no.32109) on Luminescent Image Analyzer (GE Healthcare Bio-Sciences AB, Uppsala, Sweden). Band density was quantified and normalized to $\beta$-actinby Image $\mathbf{J}$ software (version 2; National Institutes of Health).

$R T-q P C R$. Total RNA was extracted using TRIzol reagent (Thermo Fisher Scientific, Inc.) according to the manufacturer's protocol. To obtain cDNA, RT was done with the following conditions: $25^{\circ} \mathrm{C}$ for $5 \mathrm{~min}, 42^{\circ} \mathrm{C}$ for $60 \mathrm{~min}$ and $70^{\circ} \mathrm{C}$ for $15 \mathrm{~min}$. After cDNA was obtained by RT (Promega Corporation), PCR amplification was performed with forward and reverse primers using the SYBR PrimeScript RT-PCR kit (Takara Bio, Inc.) in an Mx3005p instrument (Agilent Technologies $\mathrm{GmbH}$ ). Amplification was performed with the following thermocycling conditions: $10 \mathrm{~min}$ at $95^{\circ} \mathrm{C}$, followed by 40 cycles of $95^{\circ} \mathrm{C}$ for $15 \mathrm{sec}$ and $60^{\circ} \mathrm{C}$ for $1 \mathrm{~min}$. The primers used in the present study are listed in Table I. Cq values of the test genes were normalized to the average $\mathrm{Cq}$ values of $\beta$-actin. Fold-change was calculated using the $2^{-\Delta \Delta \mathrm{Cq}}$ method (29).

Statistical analysis. All experiments were performed at least three times. Values were presented as the mean \pm standard deviation. Statistical differences were performed by one-way analysis of variance with least significant difference Duncan's post-hoc test using SPSS 21.0 for Windows (IBM, Corps.). $\mathrm{P}<0.05$ was considered to indicate a statistically significant difference between groups.

\section{Results}

Rapamycin and doxorubicin decreases the viability of K562 cells. The cytotoxic effect of doxorubicin on K562 cells was measured by the CCK- 8 assay after treating cells with increasing concentrations for 24, 48 and $72 \mathrm{~h}$ (Fig. 1). As shown in Fig. 1A, when the cells were treated with doxorubicin for $24 \mathrm{~h}$, the cell viability was significantly decreased in a dose-dependent manner $(0.03125-4 \mu \mathrm{M} ; \mathrm{r}=-0.946$; $\mathrm{P}<0.05)$. The $\mathrm{IC}_{50}$ of doxorubicin treated for $24 \mathrm{~h}$ was $3.47 \pm 0.57 \mu \mathrm{M}$. In addition, doxorubicin treatment for 48 and $72 \mathrm{~h}$ also significantly inhibited cell proliferation (48h: $r=-0.958, \mathrm{P}<0.05$; Fig. 1B; 72 h: r=-0.968; P<0.05; Fig. 1C).

In the authors' previously published paper (12), K562 cells were incubated with various concentrations of rapamycin $(5-1,000 \mathrm{nM})$ and the $\mathrm{IC}_{50}$ of rapamycin treatment for $24 \mathrm{~h}$ was $174.94 \pm 14.59 \mathrm{nM}$. To further understand the possible synergistic mechanism of rapamycin and doxorubicin, the cells were incubated with $0.125,0.25,0.5$ and $1.0 \mu \mathrm{M}$ doxorubicin, combined with 10, 20 and $40 \mathrm{nM}$ rapamycin. The cell survival rates of K562 cells were significantly decreased in the two-drug treatment group compared with the matched single-drug group and the control group $(\mathrm{P}<0.05$; Fig. 1D). Of note, the cell viability in the $0.25 \mu \mathrm{M}$ doxorubicin and $10 \mathrm{nM}$ rapamycin-treated group was $74.4 \%$, and the cell inhibition rate was $\sim 25 \%$. In addition, the CI of rapamycin and doxorubicin was analyzed using the Chou-Talalay method (30). As shown in Fig. 1D and E, when the rapamycin concentration was $>10 \mathrm{nM}$ and the doxorubicin concentration was $>0.2 \mu \mathrm{M}$, the fraction affected (at growth inhibition rates of 25\%) is higher than 0.25 and the $\mathrm{CI}$ was $<1$. According to the definition of the CI $(27,28)$, when CI is $<1$, the combination of rapamycin and doxorubicin had a synergistic inhibitory effect on the growth of K562 cells. Among these groups, the cell survival rate of K562 cells treated with $20 \mathrm{nM}$ rapamycin and $0.5 \mu \mathrm{M}$ doxorubicin was $53.4 \pm 8.20 \%$. Therefore, $20 \mathrm{nM}$ rapamycin and $0.5 \mu \mathrm{M}$ doxorubicin was chosen for the following experiments.

Rapamycin could enhance the apoptotic effect of doxorubicin on $\mathrm{K562}$ cells. To assess whether apoptosis contributes to cell growth inhibition in rapamycin and doxorubicin treatment groups, the effects of two drugs on K562 cell apoptosis were studied. The apoptotic rates following treatment with rapamycin, doxorubicin and a combination of both were 
A

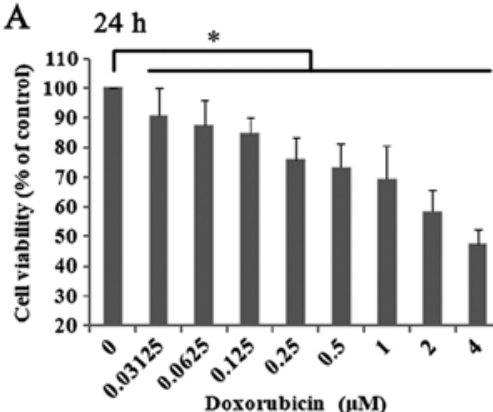

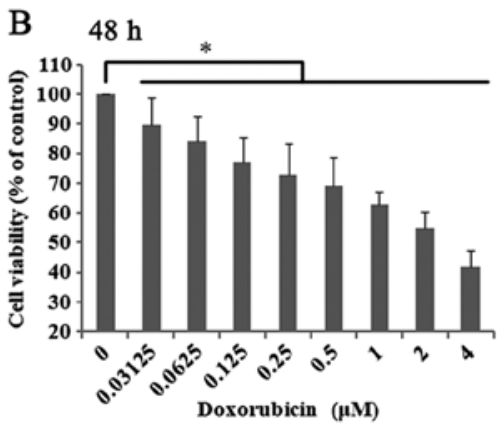

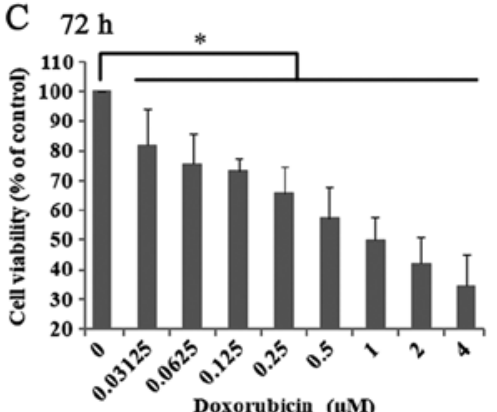

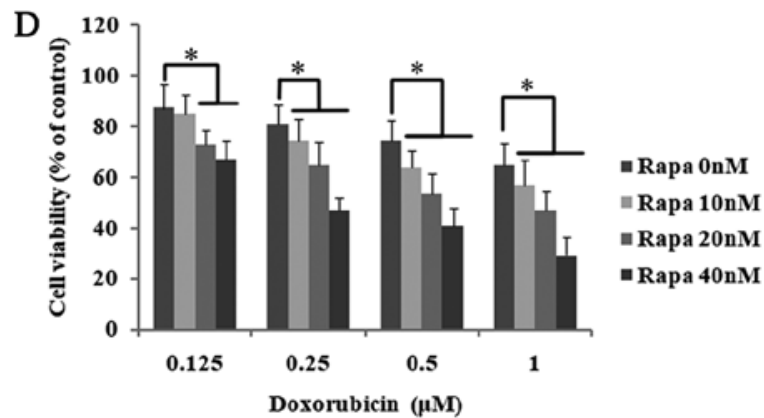

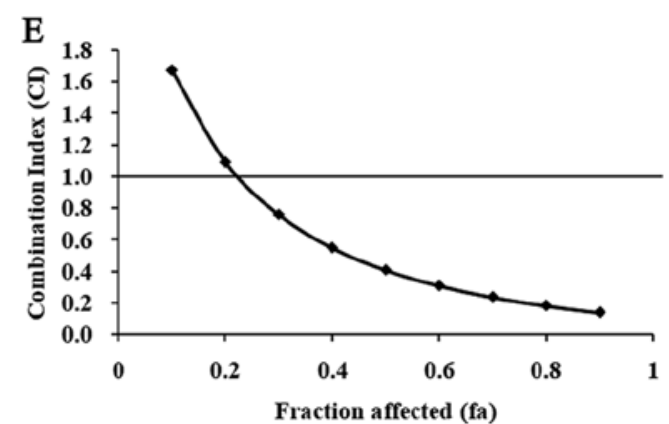

Figure 1. Rapa combined with doxorubicin decreases cell proliferation in K562 cells. Doxorubicin treatment with various concentrationsfrom $0.03125-4 \mu \mathrm{M}$ for (A) 24, (B) 48 and (C) $72 \mathrm{~h}$. The percentage of cells viability was determined by Cell Counting Kit-8 assay. Data were presented as the mean \pm SD of triplicates. " $\mathrm{P}<0.05$ vs. the solvent control group. (D) Rapa combined with doxorubicin decreased the cell viability of K562 cells. K562 cells were treated with doxorubicin $(0.125,0.25,0.5$ and $1 \mu \mathrm{M})$ and Rapa $(10,20$ and $40 \mathrm{nM})$ for $24 \mathrm{~h}$. Control value was taken as $100 \%$, and ${ }^{*} \mathrm{P}<0.05$ vs. the matched single-drug group. Data were presented as the mean \pm SD of triplicates. (E) The CI values were analyzed using the Chou-Talalay method, and the fraction affected (a growth inhibition rates of $25 \%$ ) is higher than $0.25, \mathrm{CI}<1$ indicates a synergistic effect. It suggested that Rapa enhanced the anti-proliferative effects of doxorubicin in K562 cells. Rapa, rapamycin; SD, standard deviation.

A
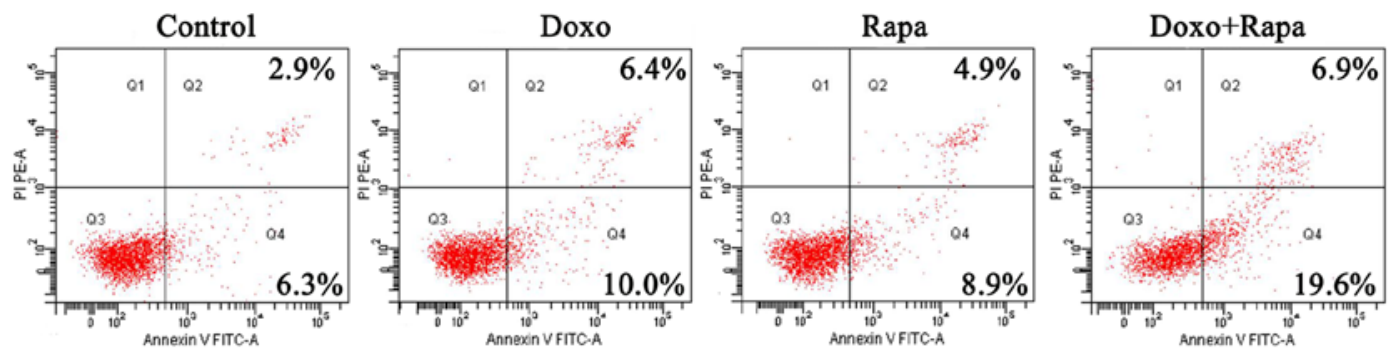

B
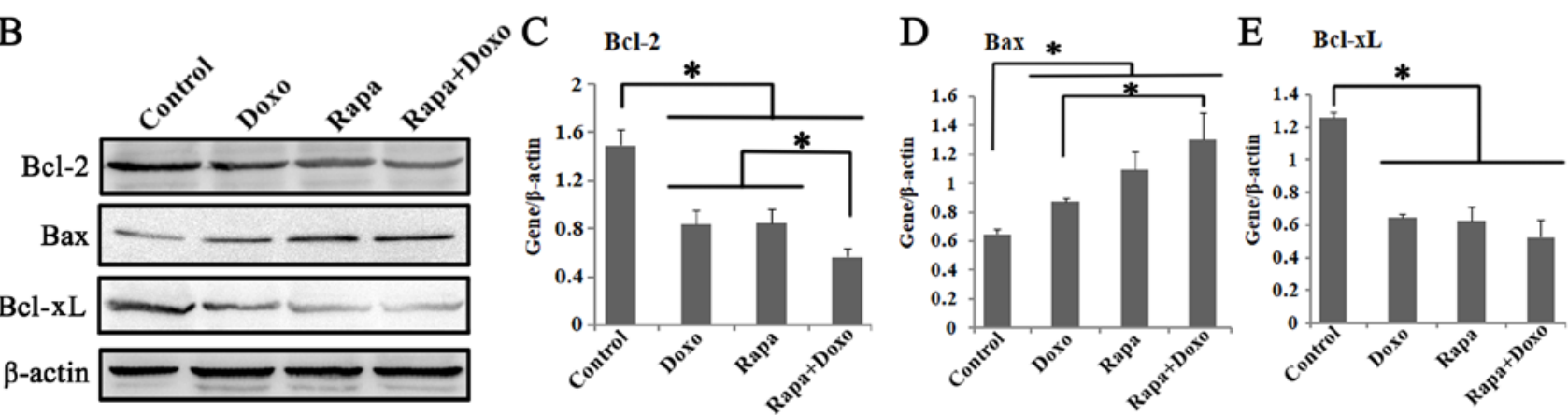

Figure 2. Rapa and Doxo induced cell apoptosis of K562 cells. Cells were incubated with Doxo $(0.5 \mu \mathrm{M})$ and Rapa (20 nM) for $24 \mathrm{~h}$. (A) Apoptosis of K562 cells was determined by Annexin V/PI apoptosis detection kit. Rapa and Doxo combination significantly increased apoptotic cells, compared with the matched single-drug group. (B) Western blotting showed the expressions of Bcl-2, Bax and Bcl-xL in Rapa, Doxo and the combination treatment group. The protein expression of (C) Bcl-2, (D) Bax and (E) Bcl-xL in K562 cells. Rapa and Doxo significantly decreased expression of (C) Bcl-2 and (E) Bcl-xL, and increase the expression of (D) Bax, respectively. ${ }^{*} \mathrm{P}<0.05$. Data were presented as the mean \pm standard deviation of triplicates. Rapa, rapamycin; Doxo, doxorubicin; FITC, fluorescein isothiocyanate; PI, propidium iodide.

significantly increased compared with in the solvent control group $(\mathrm{P}<0.05$; Fig. 2A). The apoptotic cells, I n particular, were more frequently detected in the rapamycin + doxorubicin treatment group $(25.50 \pm 1.25 \%)$ compared with rapamycin 
Table II. Effect of rapamycin and doxorubicin on apoptosis in K562 cells.

\begin{tabular}{|c|c|c|c|}
\hline \multirow[b]{2}{*}{ Group } & \multirow[b]{2}{*}{ Early } & \multicolumn{2}{|c|}{ Apoptosis (\%) } \\
\hline & & Later & Total \\
\hline Control & $5.63 \pm 0.61$ & $2.83 \pm 0.50$ & $8.47 \pm 0.95$ \\
\hline Doxo & $9.13 \pm 0.90^{\mathrm{a}}$ & $5.73 \pm 0.65^{\mathrm{a}}$ & $14.87 \pm 1.34^{\mathrm{a}}$ \\
\hline Rapa & $8.30 \pm 0.66^{\mathrm{a}}$ & $3.93 \pm 0.87$ & $12.23 \pm 1.37^{\mathrm{a}}$ \\
\hline Doxo+Rapa & $18.10 \pm 1.37^{\mathrm{a}, \mathrm{b}}$ & $7.40 \pm 0.62^{\mathrm{a}, \mathrm{b}}$ & $25.50 \pm 1.25^{\mathrm{a}, \mathrm{b}}$ \\
\hline
\end{tabular}

${ }^{\mathrm{a}} \mathrm{P}<0.05$ vs. the solvent control group; ${ }^{\mathrm{b}} \mathrm{P}<0.05$ vs. the single drug treatment. Doxo, doxorubicin; Rapa, rapamycin.

$(12.23 \pm 1.37 \%)$ and doxorubicin $(14.87 \pm 1.34 \%)$ treatment groups $(\mathrm{P}<0.05$; Fig. 2A; Table II).

To further investigate the apoptotic pathway activated by rapamycin and doxorubicin, the effects of both drugs on the expression of proteins that are pivotal for apoptosis, including $\mathrm{Bcl}-2$, Bax, and Bcl-xL, were studied. As shown in Fig. 2B, the significant downregulation of Bcl-2 and $\mathrm{Bcl}-\mathrm{xL}$ and significant upregulation of Bax were observed in rapamycin, doxorubicin, and the combination treatment group $(\mathrm{P}<0.05$; Fig. $2 \mathrm{C}-\mathrm{E})$. Of note, compared with the single-treatment group, a significantly decreased Bcl-2 and increased Bax expression were observed in the combination treatment cells $(\mathrm{P}<0.05)$. It indicated that a decrease in the $\mathrm{Bcl}-2 / \mathrm{Bax}$ ratio might be involved in the apoptotic pathways induced by rapamycin and doxorubicin in K562 cells. The above findings confirmed that rapamycin could enhance the apoptotic effect of doxorubicin on K562 cells.

Inactivation of the mTOR/p70S6K pathway in rapamycin- and doxorubicin-treated $K 562$ cells. The effects of rapamycin and doxorubicin on the mTOR/p70s6k pathway in K562 cells were investigated by western blot analysis. As shown in Fig. 3A, although the total mTOR expression showed slight changes in K562 cells, the phosphorylation level of mTOR (Ser-2448) treated with rapamycin, doxorubicin and a combination of both was significantly decreased compared with in the solvent-treated control group $(\mathrm{P}<0.05$; Fig. 3A). The expression of p70S6K was also investigated. Rapamycin, doxorubicin and a combination of both induced a significant decrease in the total and the phosphorylation level of p70S6K (Thr-389) in $\mathrm{K} 562$ cells ( $\mathrm{P}<0.05$; Fig. 3B). In addition, p70S6K and its phosphorylated form were significantly decreased in cells treated with both drugs compared with those treated with rapamycin or doxorubicin alone ( $\mathrm{P}<0.05$; Fig. $3 \mathrm{~B})$.

p70S6K siRNA decreases the expression of p70S6K in K562 cells. To understand the role of p70S6K in the rapamycin pathway, K562 cells were transfected with targeting siRNA to block p70S6K. The successful knockdown of p70S6K was confirmed by RT-qPCR and western blot analysis. Compared with the control siRNA group, the mRNA expression of p70S6K was significantly decreased to $\sim 1 / 5$ in p70S6K targeting siRNA cells $(\mathrm{P}<0.05$; Fig. 4A). Furthermore, western blot analysis results showed that the p70S6K expression was markedly decreased in the p70S6K siRNA treatment group (Fig. 4B). The present data showed that the p70S6K-targeting siRNA effectively downregulated the expression of p70S6K.

p70S6K downregulation enhances the inhibitory effect of doxorubicin on cell proliferation. To investigate the role of p70S6K in the inhibitory effect of rapamycin and doxorubicin on cell proliferation, cell viability was further detected following treatment with p70S6K siRNA and doxorubicin. The CCK-8 assay results showed that p70S6K-targeting siRNA and doxorubicin treatment significantly decreased cell proliferation compared with the p70S6K siRNA, doxorubicin and control siRNA groups ( $\mathrm{P}<0.05$; Fig. $4 \mathrm{C})$.

Certain critical proteins involved in cell proliferation were also investigated by western blot analysis and RT-qPCR. The knockdown of p70S6K and doxorubicin treatment significantly decreased the mRNA and protein expression of CDK4, CDK6, cyclin D1 and cyclin B1 (P<0.05; Fig. 4D and E). These results may suggest that rapamycin could enhance the inhibitory effect of doxorubicin on cell proliferation by downregulating the mTOR/p70S6K pathway in K562 cells.

p70S6K downregulation enhances the doxorubicin-induced K562 cell apoptosis. To study whether the cytotoxic effects of treatment with p70S6K siRNA and doxorubicin are associated with enhanced apoptosis, cell apoptosis was examined by FCM. K562 cells were treated with p70S6K siRNA, doxorubicin alone and a combination of both. The results showed that the knockdown of p70S6K and doxorubicin treatment significantly increased the early, late and total apoptotic rates, as compared with the control group ( $\mathrm{P}<0.05$; Fig. 5A and $\mathrm{B})$. Compared with single treatment, the exposure of cells to p70S6K siRNA and doxorubicin significantly increased apoptosis ( $\mathrm{P}<0.05$; Fig. 5A and $\mathrm{B})$. In addition, western blot analysis results showed a decreased expression of Bcl-2 and increased expression of Bax in K562 cells treated with p70S6K siRNA and doxorubicin (Fig. 5C). These data suggested that blocking p70S6K signaling could enhance doxorubicin-induced K562 cell apoptosis.

\section{Discussion}

Despite the fact that Bcr/Abl kinase inhibitors have significantly improved life expectancy in the majority of patients in the chronic phase of CML, certain patients progressing to the blast phase will develop Bcr/Abl-independent mechanisms of resistance. This patient population requires chemotherapeutics, including doxorubicin and cytarabine, or needs an alternative drug target that can be inhibited with a novel compound. Certain studies have shown that mTOR signaling is frequently activated in CML (8-12). In addition, Bcr/Abl kinase could regulate PI3K activity through its regulatory subunit and mTOR was subsequently activated by the phosphorylation of AKT in CML cell lines (15). It was found in the authors' previous studies that rapamycin markedly inhibited cell growth and enhanced the antitumor effects of celecoxib on CML cells by downregulating the mTOR pathway $(12,17)$. It is well known that mTOR exists in two multiprotein complexes, mTORC1 and mTORC2. The main function of mTORC1 
A

A
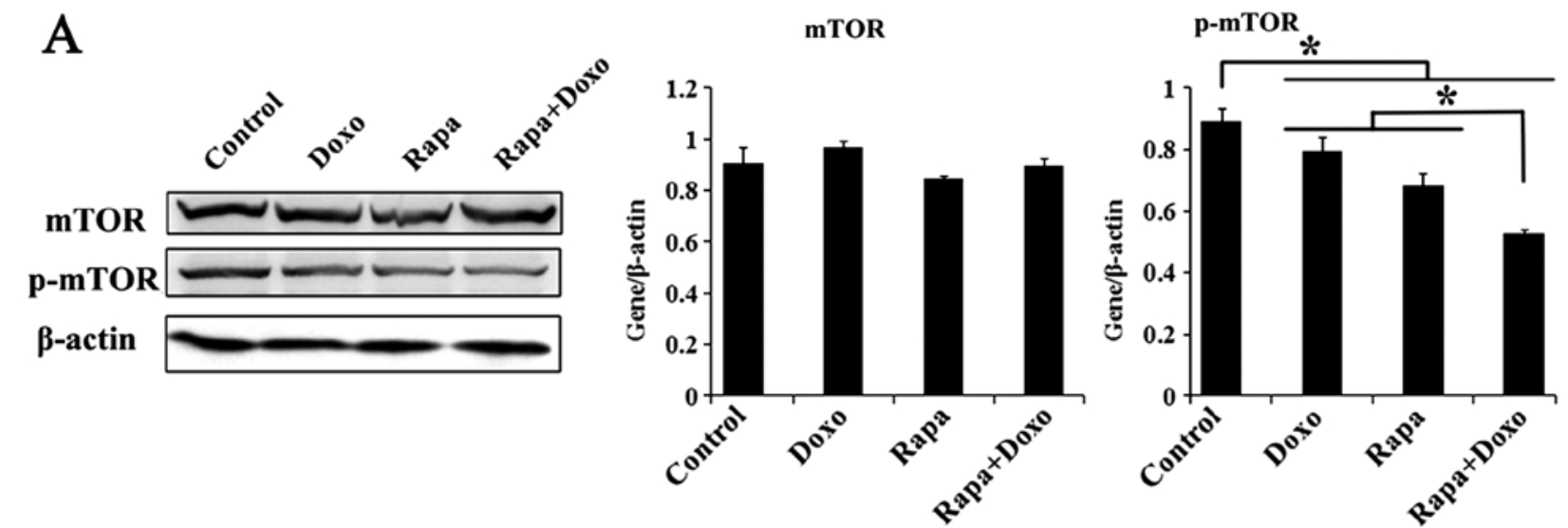

B
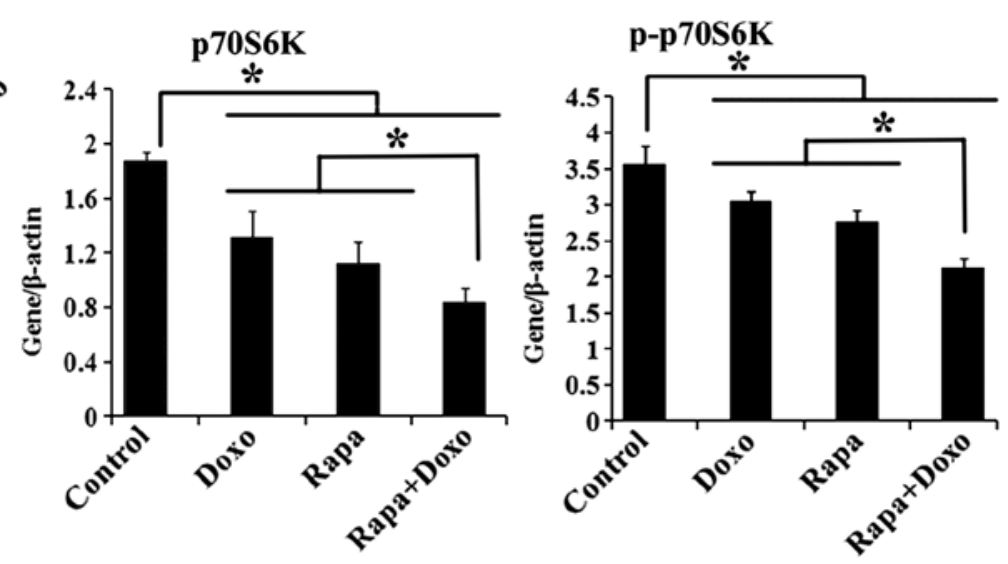

Figure 3. Rapa and Doxo inhibit expression of mTOR/p70S6K signaling. Cells were cultured with Doxo $(0.5 \mu \mathrm{M})$, Rapa (20 nM) or combination treatment. Total protein was extracted, followed by immunoblotting with mTOR, p-mTOR (Ser-2448), p70S6K, p-p70S6K (Thr-389) and $\beta$-actin antibodies. Experiments were repeated 3 times and data were presented as the mean \pm standard deviation of triplicates. (A) mTOR phosphorylation (Ser-2448) was significantly decreased compared with the solvent control group and the matched single-drug group. "P<0.05. (B) Rapa, Doxo, alone or combination treatment decreased the expression of p70S6K and its phosphorylation (Thr-389) * $\mathrm{P}<0.05$. Rapa, rapamycin; Doxo, doxorubicin; $\mathrm{p}$-mTOR, phosphorylated-mammalian target of rapamycin; p70S6K, ribosomal protein S6 kinase.

which phosphorylates p70S6K and 4E-BP1, is sensitive to nutrients and rapamycin. In contrast to mTORC1, mTORC2 which is insensitive to rapamycin, could phosphorylate AKT at Ser473 and forms a feedback loop (31). Certain studies have demonstrated that an mTOR inhibitor, combined additively or synergistically with several chemotherapies, such aspaclitaxel, doxorubicin and carboplatin, could inhibit cancer cells proliferation in vitro (32-34). Collectively, targeting the mTOR pathway may be a new therapeutic approach. However, the mechanisms through which rapamycin may have synergistic effects with doxorubicin on leukemia cells remain virtually unknown.

To further explore the possible synergistic mechanisms of rapamycin and doxorubicin on cell growth, K562 cells were cultured with a combination of various concentrations. According to the authors' published paper (12), the $\mathrm{IC}_{50}$ of rapamycin treatment for $24 \mathrm{~h}$ is $174.94 \pm 14.59 \mathrm{nM}$. It was reported that the distribution volume of doxorubicin varies markedly in different patients or for different cell lines (23-26). Therefore, to investigate effects of doxorubicin on cell proliferation, K562 cells were cultured with various concentrations from $0.03125-4 \mu \mathrm{M}$. The results showed that doxorubicin decreased K562 cells in a dose-dependent manner and $\mathrm{The} \mathrm{IC}_{50}$ of doxorubicin treatment for $24 \mathrm{~h}$ was $3.47 \pm 0.57 \mu \mathrm{M}$. The cell survival rates of $\mathrm{K} 562$ cells were markedly lower in two-drug treatment group than in the matched single-drug group. Meanwhile, when the rapamycin concentration was $>10 \mathrm{nM}$, the doxorubicin concentration was $>0.2 \mu \mathrm{M}$, and the growth inhibition rates is higher than $25 \%$, CI was less than $1(\mathrm{CI}<1)$. Co-incubation markedly increased the response of K562 cells to doxorubicin, indicating that rapamycin synergistically enhance the anti-proliferative effects of doxorubicin in K562 cells.

In addition, cell apoptosis was measured in rapamycinand doxorubicin-treated K562 cells. The results showed that individual treatment can induce cell apoptosis and regulate the expression of Bcl-2, Bax and Bcl-xL. As compared with single-drug treatment, rapamycin combined with doxorubicin increased cell apoptosis. It has been demonstrated that the Bcl-2 family members regulate the cell apoptotic pathway. In particular, increasing Bax expression and/or decreasing Bcl-2 expression may induce apoptosis (35). The present results showed that both drugs induced Bcl-2 downregulation and Bax upregulation, resulting in a decrease in the Bcl-2/Bax ratio. It was also found that rapamycin and doxorubicin can decrease the phosphorylation of mTOR and p70S6K. A recent study found combined treatment with rapamycin and melatonin to be associated with increased apoptosis and mitophagy in head and neck cancers (33). These findings suggested that rapamycin enhances the apoptotic effect of doxorubicin on K562 cells through the mTOR/p70S6K pathway. 

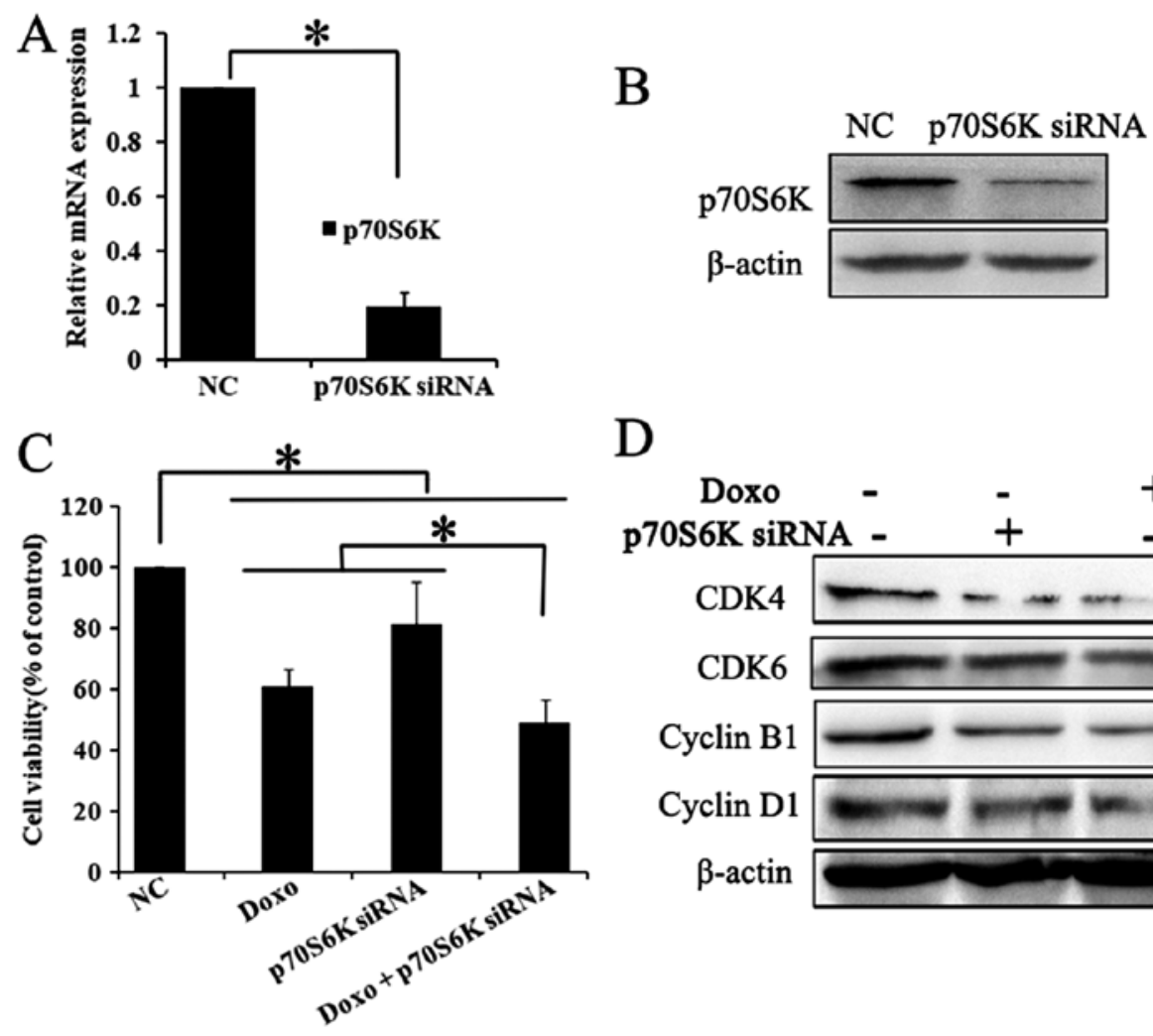

\section{$\mathrm{D}$}
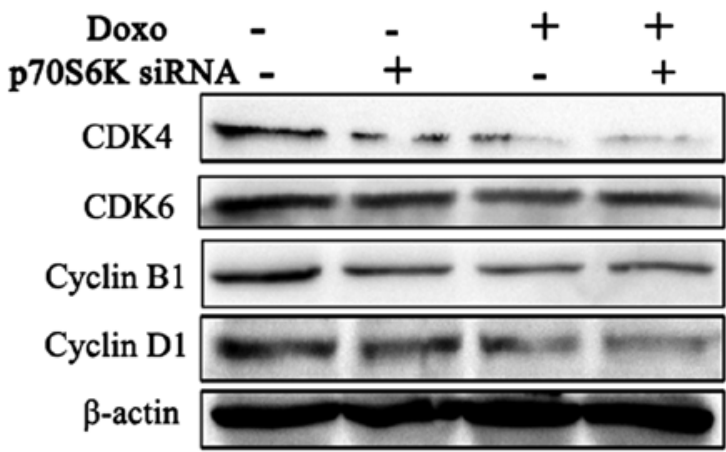

$\mathrm{E}$

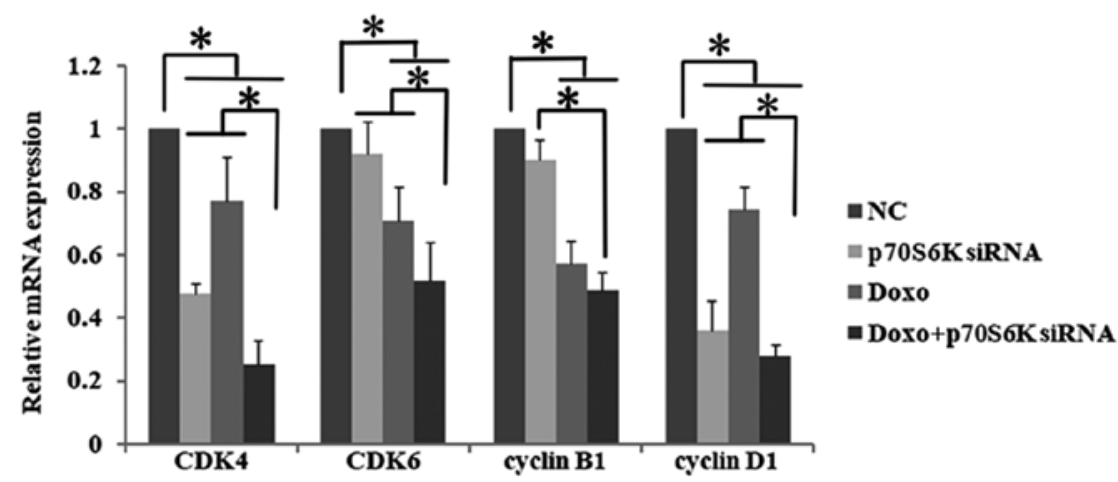

Figure 4. p70S6K knock down enhances the anti-proliferative effects of Doxo in K562 cells. K562 cells were cultured and transfected with p70S6K targeting siRNA for $48 \mathrm{~h}$. Successful knockdown of p70S6K was confirmed by (A) RT-qPCR and (B) western blot assays. The results showed that targeting siRNA significantly decreased the expression of p70S6K, compared with the control siRNA group. "P<0.05. Data were presented as mean \pm SD of triplicates. (C) Cells were cultured with Doxo $(0.5 \mu \mathrm{M})$ after p70S6K knockdown, the cell viability was determined by Cell Counting Kit- 8 . The exposure of p70S6K knockdown and doxorubicin alone or combination significantly inhibited cell viability. ${ }^{*} \mathrm{P}<0.05$. The values are represented as the mean \pm SD. The expression of cell cycle molecules were detected using (D) western blotting and (E) RT-qPCR. The expression of CDK4, CDK6, cyclin B1 and cyclin D1 were significantly decreased in p70S6K knockdown and Doxo treatment group compared withthe single treatment group and the control group. ${ }^{*} \mathrm{P}<0.05$. Data were presented as mean $\pm \mathrm{SD}$ of triplicates. CDK, cyclin dependent kinases; SD, standard deviation; RT-q, reverse transcription-quantitative; si, small interfering; Doxo, doxorubicin; p70S6K, ribosomal protein S6 kinase.

As is known, 4EBP1 and p70S6K are the two most important downstream proteins of the mTOR pathway. The phosphorylation of 4E-BP1 (Ser37; Thr46; Ser65; Thr70) regulates cap-dependent transcription and translation of a great number of proteins. On the other hand, activated p70S6K could increase the translation of 5'-terminal oligopyrimidine tract mRNAs, regulates protein synthesis and plays a critical role in controlling cell growth (36). Extensive evidence has revealed that the overexpression and phosphorylation of p70S6K promotes cell proliferation, angiogenesis and suppression of apoptosis in vitro $(37,38)$, whereas, the p70S6K specific inhibitor (PF-4708671) has inhibitory effects on non-small cell lung cancer in vitro and in vivo (39). High p70S6K phosphorylation has also been reported to be an independent biomarker of poor prognosis in right-sided colorectal cancer (20). Similar observations of the p-p70S6K prognostic function have been made for lung, esophagealand ovarian cancer, and hepatocellular carcinoma (40-42).

Studies havepreviously demonstrated that overexpression of p70S6K in tumor tissues contributes to chemotherapy resistance (43). High levels of p-p70S6K were involved in selumetinib resistance, and the inhibition of p70S6K could reverse this chemotherapeutic resistance in colorectal cancer (44). The authors have previously found that the inhibition of p70S6K by rapamycin was additionally associated with an increased number of $G_{0} / G_{1}$ cells and apoptotic cells in 

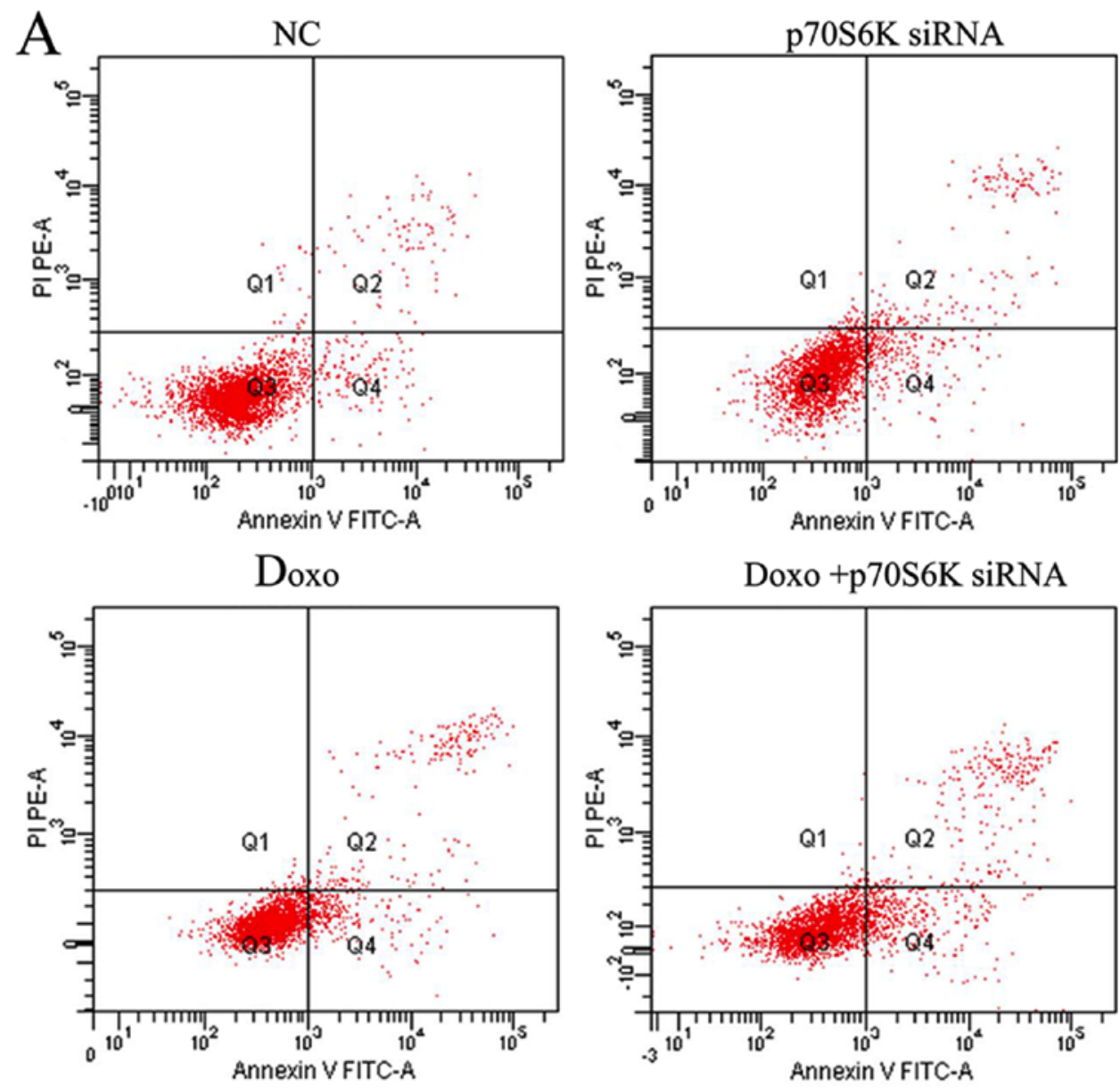

B

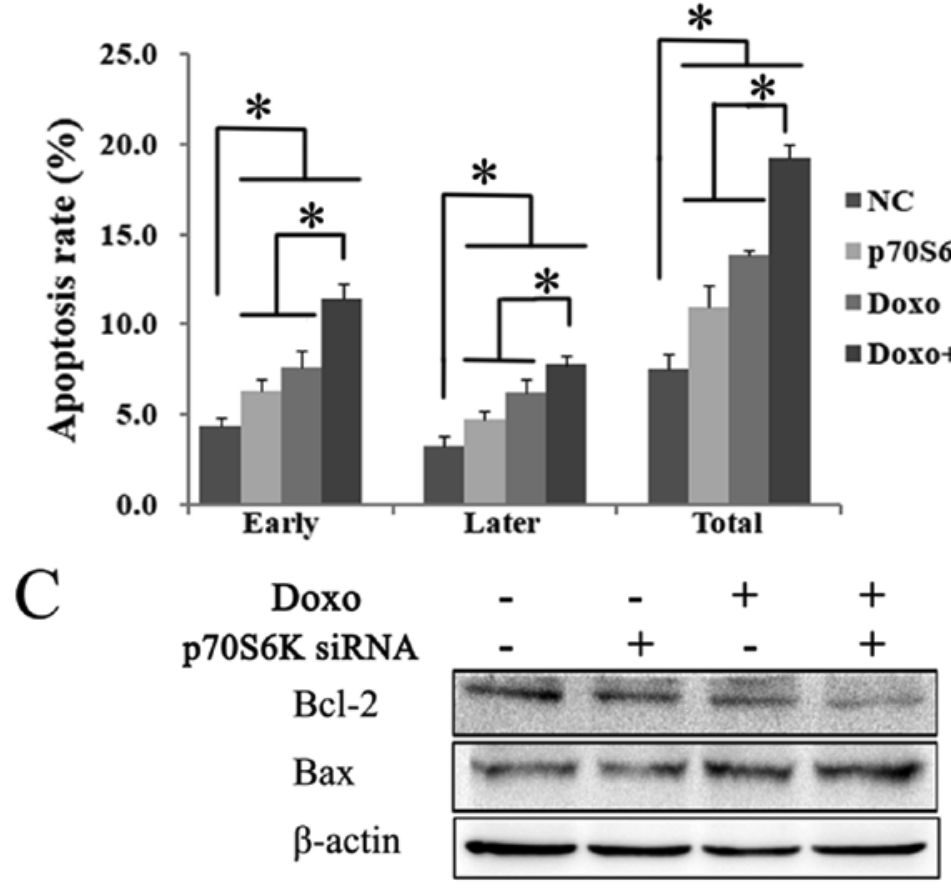

Figure 5. p70S6K knock down enhances Doxo-induced cell apoptosis. (A) Cell apoptosis were detected by flow cytometry analysis. (B) p70S6K knock down and Doxo treatment significantly increased the early apoptotic, late apoptotic and total apoptotic cells than the single treatment group and the control group. ${ }^{*} \mathrm{P}<0.05$. The values are represented as the mean \pm standard deviation. (C) Western blot results showed the significantly lower expression of Bcl-2 and higher expression of Bax in p70S6K knockdown and Doxo treatment group. It suggested that p70S6K knock down enhance Doxo-induced cell apoptosis. Doxo, doxorubicin; NC, negative control; FITC, fluorescein isothiocyanate; PI, propidium iodide; p70S6K, ribosomal protein S6 kinase.

leukemia, while rapamycin combined with celecoxib enhanced this effect $(12,17)$. A more recent study showed p70S6K1 suppressed autophagy through inhibiting AMPK and JNK in a TAK1-dependent manner (45). 
In the present study, a p70S6K-targeting siRNA was used as an inhibitor to knockdown p70S6K and more attention was paid to investigate its mechanism. It was found that p70S6K knockdown and doxorubicin treatment decreased cell proliferation, compared with the single treatment. The p70S6K siRNA and doxorubicin clearly decreased the expression of CDK4, CDK6, cyclin D1 and cyclin B1, as compared with the control and single-treatment groups. These molecules are key elements in the cell cycle and serve an essential role in the progression of various types of cancer. Among these, cyclin D1 binding to CDK4 is triggered at the early stage of the $\mathrm{G}_{1}$ phase. The inhibition of cyclin D1 or CDK4 partly restores $\mathrm{G}_{1} / \mathrm{S}$ arrest and sensitizes cells to doxorubicin-mediated cell apoptosis, significantly overcoming doxorubicin resistance $(46,47)$. The authors have previously demonstrated that rapamycin arrested K562 cells at the $G_{0} / G_{1}$ phase through mTOR and its downstream molecules $(12,15)$. The present study showed that the downregulation of p70S6K could inhibit CDK4 and cyclin D1 expression. In addition, compared with single treatment, the knockdown of p70S6K and doxorubicin treatment significantly increased cell apoptosis. Furthermore, western blot analysis results showed that p70S6K siRNA and doxorubicin regulate the expression of Bcl-2 and Bax in K562 cells. It suggested that rapamycin synergistically enhanced the doxorubicin-induced inhibition of cell proliferation and apoptosis through the mTOR/p70S6K pathway in K562 cells.

In conclusion, these findings showed that rapamycin and doxorubicin synergistically inhibited cell growth, induced apoptosis, and decreased the expression of mTOR/p70S6K. In addition, p70S6K blocking by siRNA, combined with doxorubicin, could inhibit cell proliferation and induce apoptosis in K562 cells. The authors' preliminary results suggested that rapamycin may enhance the antitumor effects of doxorubicin on K562 cells by downregulating mTOR/p70S6K signaling. Targeting the mTOR pathway may be a more suitable therapeutic approach for leukemia.

\section{Acknowledgements}

Not applicable.

\section{Funding}

The present study was supported by the Natural Science Foundation of Hebei Province (grant no. H2017307024) and the Project of Health Department of Hebei Province (grant no. 20170030).

\section{Availability of data and materials}

The datasets used and/or analyzed during the current study are available from the corresponding author on reasonable request.

\section{Authors' contributions}

$\mathrm{JL}$ and LX designed the study, analyzed the data and wrote the manuscript. WL and QW performed the experiments and prepared the figures. HH designed the study, prepared the figures and analyzed the data. JL and LX performed critical revision of the manuscript and supervised the study. All authors have read and approved the final manuscript.

\section{Ethics approval and consent to participate}

The study was approved by the Ethics Committee of Hebei General Hospital (Shijiazhuang, China).

\section{Patient consent for publication}

Not applicable.

\section{Competing interests}

The authors declare that they have no competing interests.

\section{References}

1. Rowley JD: Ph1-positive leukaemia, including chronic myelogenous leukaemia. Clin Haematol 9: 55-86, 1980

2. Groffen J, Stephenson JR, Heisterkamp N, de Klein A Bartram CR and Grosveld G: Philadelphia chromosomal breakpoints are clustered within a limited region, bcr, on chromosome 22. Cell 36: 93-98, 1984.

3. Gorre ME, Mohammed M, Ellwood K, Hsu N, Paquette R, Rao PN and Sawyers CL: Clinical resistance to STI-571 cancer therapy caused by BCR-ABL gene mutation or amplification. Science 293: 876-880, 2001

4. Okabe S, Tauchi T, Tanaka Y, Kitahara T, Kimura S, Maekawa T and Ohyashiki K: Efficacy of the dual PI3K and mTOR inhibitor NVP-BEZ235 in combination with nilotinib against BCR-ABL-positive leukemia cells involves the ABL kinase domain mutation. Cancer Biol Ther 15: 207-215, 2014.

5. Sun Z, Li Q, Zhang S, Chen J, Huang L, Ren J, Chang Y, Liang Y and Wu G: NVP-BEZ235 overcomes gefitinib-acquired resistance by down-regulating PI3K/AKT/mTOR phosphorylation. Onco Targets Ther 8: 269-277, 2015.

6. Xu J, Pham CG, Albanese SK, Dong Y, Oyama T, Lee CH, Rodrik-Outmezguine V, YaoZ,HanS, ChenD, et al: Mechanistically distinct cancer-associated mTOR activation clusters predict sensitivity to rapamycin. J Clin Invest 126: 3526-3540, 2016.

7. Morran DC, Wu J, Jamieson NB, Mrowinska A, Kalna G, Karim SA, Au AY, Scarlett CJ, Chang DK, Pajak MZ, et al: Targeting mTOR dependency in pancreatic cancer. Gut 63 : 1481-1489, 2014.

8. Mohi MG, Boulton C, Gu TL, Sternberg DW, Neuberg D, Griffin JD, Gilliland DG and Neel BG: Combination of rapamycin and protein tyrosine kinase (PTK) inhibitors for the treatment of leukemias caused by oncogenic PTKs. Proc Natl Acad Sci USA 101: 3130-3135, 2004.

9. Parmar S, Smith J, Sassano A, Uddin S, Katsoulidis E, Majchrzak B, Kambhampati S, Eklund EA, Tallman MS, Fish EN and Platanias LC: Differential regulation of the p70 S6 kinase pathway by interferon alpha (IFNalpha) and imatinib mesylate (STI571) in chronic myelogenous leukemia cells. Blood 106: 2436-2443, 2005.

10. Hirase C, Maeda Y, Takai S and Kanamaru A: Hypersensitivity of Ph-positive lymphoid cell lines to rapamycin: Possible clinical application of mTOR inhibitor. Leuk Res 33: 450-459, 2009.

11. Batista A, Barata JT, Raderschall E, Sallan SE, Carlesson N, Nadler LM and Cardoso AA: Targeting of active mTOR inhibits primary leukemia $\mathrm{T}$ cells and synergizes with cytotoxic drugs and signaling inhibitors. Exp Hematol 39: 457-472.e3, 2011.

12. Li J, Xue L, Hao H, Han Y, Yang J and Luo J: Rapamycin provides a therapeutic option through inhibition of mTOR signaling in chronic myelogenous leukemia. Oncol Rep 27: 461-466, 2012.

13. LoPiccolo J, Blumenthal GM, Bernstein WB and Dennis PA: Targeting the PI3K/Akt/mTOR pathway: Effective combinations and clinical considerations. Drug Resist Updat 11: 32-50, 2008.

14. Guo N, Azadniv M, Coppage M, Nemer M, Mendler J, Becker M and Liesveld J: Effects of neddylation and mTOR inhibition in acute myelogenous leukemia. Transl Oncol 12: 602-613, 2019. 
15. Ly C, Arechiga AF, Melo JV, Walsh CM and Ong ST: Bcr-Abl kinase modulates the translation regulators ribosomal protein S6 and 4E-BP1 in chronic myelogenous leukemia cells via the mammalian target of rapamycin. Cancer Res 63: 5716-5722, 2003.

16. Xin P, Li C, Zheng Y, Peng Q, Xiao H, Huang Y and Zhu X: Efficacy of the dual PI3K and mTOR inhibitor NVP-BEZ235 in combination with imatinib mesylate against chronic myelogenous leukemia cell lines. Drug Des Devel Ther 11: 1115-1126, 2017.

17. Li J, Xue L, Hao H, Li R and Luo J: Rapamycin combined with celecoxib enhanced antitumor effects of mono treatment on chronic myelogenous leukemia cells through downregulating mTOR pathway. Tumour Biol 35: 6467-6474, 2014.

18. Harada H, Andersen JS, Mann M, Terada N and Korsmeyer SJ: p70S6 kinase signals cell survival as well as growth, inactivating the pro-apoptotic molecule BAD. Proc Natl Acad Sci USA 98 9666-9670, 2001.

19. Xie Y, Naizabekov S, Chen Z and Tokay T: Power of PTEN/AKT: Molecular switch between tumor suppressors and oncogenes. Oncol Lett 12: 375-378, 2016.

20. Vicary GW and Roman J: Targeting the mammalian target of rapamycin in lung cancer. Am J Med Sci 352: 507-516, 2016.

21. Kurgan N, Tsakiridis E, Kouvelioti R, Moore J, Klentrou P and Tsiani E: Inhibition of human lung cancer cell proliferation and survival by post-exercise serum is associated with the inhibition of Akt, mTOR, p70 S6K, and Erk1/2. Cancers (Basel) 9: E46, 2017.

22. Wiesweg M, Reis H,Köster T, Goetz M, Worm K, Herold T, Paul A, Dechêne A, Schumacher B, Markus P, et al: Phosphorylation of p70 ribosomal protein S6 kinase $\beta-1$ is an independent prognostic parameter in metastatic colorectal cancer. Clin Colorectal Cancer 17: e331-e352, 2018.

23. Morjani H, Pignon B, Millot JM, Debal V, Lamiable D, Potron G, Etienne JC and Manfait M: Intranuclear concentration measurements of doxorubicin in living leucocytes from patients treated for a lympho-proliferative disorder. Leuk Res 16: 647-653, 1992

24. Speth PA, Linssen PC, Termond EF, Boezeman JB, Wessels HM and Haanen C: In vivo and in vitro pharmacokinetic differences between four structurally closely related anthracyclines in hematopoietic cell subtypes in humans. Drug Metab Dispos 17: 98-105, 1989

25. Skorkina MY, Shamray EA, Salo VA, Buchelnikov AS and Evstigneev MP: Study of the properties of doxorubicin-resistant cells affected by acute leucosis. J Bioenerg Biomembr 50: 53-58, 2018.

26. Chekin F, Myshin V, Ye R, Melinte S, Singh SK, Kurungot S, Boukherroub R and Szunerits S: Graphene-modified electrodes for sensing doxorubicin hydrochloride in human plasma. Anal Bioanal Chem 411: 1509-1516, 2019.

27. Jin ZJ: Addition in drug combination (author's transl). Zhongguo Yao Li Xue Bao 1: 70-76, 1980 (In Chinese).

28. Ding Y, Niu W, Zhang T, Wang J, Cao J, Chen H, Wang R and An H: Levistolide A synergistically enhances doxorubicin-induced apoptosis of k562/dox cells by decreasing MDR1 expression through the ubiquitin pathway. Oncol Rep 41: 1198-1208, 2019.

29. Livak KJ and Schmittgen TD: Analysis of relative gene expression data using real-time quantitative PCR and the 2(-Delta Delta C(T)) method. Methods 25: 402-408, 2001

30. Chou TC: Theoretical basis, experimental design, and computerized simulation of synergism and antagonism in drug combination studies. Pharmacol Rev 58: 621-681, 2006.

31. Yuan HX and Guan KL: The SIN1-PH domain connects mTORC2 to PI3K. Cancer Discov 5: 1127-1129, 2015.

32. MondesireWH, Jian W, Zhang H,Ensor J,Hung MC, Mills GB and Meric-Bernstam F: Targeting mammalian target of rapamycin synergistically enhances chemotherapy-induced cytotoxicity in breast cancer cells. Clin Cancer Res 10: 7031-7042, 2004.
33. Shen YQ, Guerra-Librero A, Fernandez-Gil BI, Florido J, García-López S, Martinez-Ruiz L, Mendivil-Perez M, Soto-Mercado V, Acuña-Castroviejo D, Ortega-Arellano H, et al: Combination of melatonin and rapamycin for head and neck cancer therapy: Suppression of AKT/mTOR pathway activation, and activation of mitophagy and apoptosis via mitochondrial function regulation. J Pineal Res 64, 2018.

34. Hsu PY, Wu VS, Kanaya N, Petrossian K, Hsu HK, Nguyen D, Schmolze D, Kai M, Liu CY, Lu H, et al: Dual mTOR kinase inhibitor MLN0128 sensitizes $\mathrm{HR}^{+} / \mathrm{HER}^{+}$breast cancer patient-derived xenografts to trastuzumab or fulvestrant. Clin Cancer Res 24: 395-406, 2018.

35. Zheng JH, Viacava Follis A, Kriwacki RW and Moldoveanu T: Discoveries and controversies in BCL-2 protein-mediated apoptosis. FEBS J 283: 2690-2700, 2016.

36. Ma XM and Blenis J: Molecular mechanisms of mTOR-mediated translational control. Nat Rev Mol Cell Biol 10: 307-318, 2009.

37. Bian CX, Shi Z, Meng Q, Jiang Y, Liu LZ and Jiang BH: P70S6K 1 regulation of angiogenesis through VEGF and HIF-1alpha expression. Biochem Biophys Res Commun 398: 395-399, 2010.

38. Yamnik RL, Digilova A, Davis DC, Brodt ZN, Murphy CJ and Holz MK: S6 kinase 1 regulates estrogen receptor alpha in control of breast cancer cell proliferation. J Biol Chem 284: 6361-6369, 2009.

39. Qiu ZX, Sun RF, Mo XM and Li WM: The p70S6K specific inhibitor PF-4708671 impedes non-small cell lung cancer growth. PLoS One 11: e0147185, 2016.

40. Baba HA, Wohlschlaeger J, Cicinnati VR, Hilgard P, Lang H, Sotiropoulos GC, Takeda A, Beckebaum S and Schmitz KJ: Phosphorylation of p70S6 kinase predicts overall survival in patients with clear margin-resected hepatocellular carcinoma. Liver Int 29: 399-405, 2009.

41. Li SH, Chen CH, Lu HI, Huang WT, Tien WY, Lan YC, Lee CC, Chen YH, Huang HY, Chang AY and Lin WC: Phosphorylated p70S6K expression is an independent prognosticator for patients with esophageal squamous cell carcinoma. Surgery 157: 570-580, 2015.

42. No JH, Jeon YT, Park IA, Kim YB, Kim JW, Park NH, Kang SB, Han JY, Lim JM and Song YS: Activation of mTOR signaling pathway associated with adverse prognostic factors of epithelial ovarian cancer. Gynecol Oncol 121: 8-12, 2011.

43. Yoshida S, Matsumoto K, Arao T, Taniguchi H, Goto I, Hanafusa T, Nishio K and Yamada Y: Gene amplification of ribosomal protein S6 kinase-1 and -2 in gastric cancer. Anticancer Res 33: 469-475, 2013.

44. Grasso S, Tristante E, Saceda M, Carbonell P, Mayor-López L, Carballo-Santana M, Carrasco-García E, Rocamora-Reverte L, García-Morales P, Carballo F, et al: Resistance to Selumetinib (AZD6244) in colorectal cancer cell lines is mediated by p70S6K and RPS6 activation. Neoplasia 16: 845-860, 2014.

45. Xu X, Sun J, Song R, Doscas ME, Williamson AJ, Zhou J, Sun J, Jiao X, Liu X and Li Y: Inhibition of p70 S6 kinase (S6K1) activity by A77 1726, the active metabolite of leflunomide, induces autophagy through TAK1-mediated AMPK and JNK activation. Oncotarget 8: 30438-30454, 2017.

46. Ji ZP, Qiang L and Zhang JL: Transcription activated p73-modulated cyclin D1 expression leads to doxorubicin resistance in gastric cancer. Exp Ther Med 15: 1831-1838, 2018.

47. Gogolin S, Ehemann V, Becker G, Brueckner LM, Dreidax D, Bannert S, Nolte I, Savelyeva L, Bell E and Westermann F: CDK4 inhibition restores G(1)-S arrest in MYCN-amplified neuroblastoma cells in the context of doxorubicin-induced DNA damage. Cell Cycle 12: 1091-1104, 2013.

This work is licensed under a Creative Commons Attribution-NonCommercial-NoDerivatives 4.0 International (CC BY-NC-ND 4.0) License. 